\title{
Article
}

\section{High-Efficiency Ho:YAP Pulse Laser Pumped at 1989 nm}

\author{
Chao Niu ${ }^{1}$, Yan Jiang ${ }^{1}$, Ya Wen ${ }^{1}$, Lu Zhao ${ }^{1}$, Xinyu Chen ${ }^{1}$, Chunting Wu ${ }^{1, *}$ and Tongyu Dai ${ }^{2}$ \\ 1 Jilin Key Laboratory of Solid-State Laser Technology and Application, Changchun University of Science and \\ Technology, Changchun 130022, China; leoniuc@163.com (C.N.); moyudaidai@yeah.net (Y.J.); \\ winvene@163.com (Y.W.); sasslh@163.com (L.Z.); chenxinyucust@163.com (X.C.) \\ 2 National Key Laboratory of Tunable Laser Technology, Harbin Institute of Technology, Harbin 150001, China; \\ daitongyu2006@126.com \\ * Correspondence: bigsnow@cust.edu.cn
}

check for

updates

Citation: Niu, C.; Jiang, Y.; Wen, Y.; Zhao, L.; Chen, X.; Wu, C.; Dai, T.

High-Efficiency Ho:YAP Pulse Laser Pumped at $1989 \mathrm{~nm}$. Crystals 2021, 11, 595. https://doi.org/10.3390/ cryst11060595

Academic Editors: Xiaoming Duan, Renqin Dou, Linjun Li and Xiaotao Yang

Received: 19 April 2021

Accepted: 18 May 2021

Published: 24 May 2021

Publisher's Note: MDPI stays neutral with regard to jurisdictional claims in published maps and institutional affiliations.

Copyright: (c) 2021 by the authors. Licensee MDPI, Basel, Switzerland. This article is an open access article distributed under the terms and conditions of the Creative Commons Attribution (CC BY) license (https:/ / creativecommons.org/licenses/by/ $4.0 /)$.
Abstract: A Tm:YAP laser with an output wavelength of $1989 \mathrm{~nm}$ was selected for the first time as the pump source of a Q-switched Ho:YAP laser. When the absorbed power was $30 \mathrm{~W}$, an average power of $18.02 \mathrm{~W}$ with the pulse width of $104.2 \mathrm{~ns}$ acousto-optic (AO) Q-switched Ho:YAP laser was obtained at a repetition frequency of $10 \mathrm{kHz}$. The slope efficiency was $70.11 \%$, and the optical-optical conversion efficiency was $43.03 \%$. The output center wavelength was $2129.22 \mathrm{~nm}$ with the line width of $0.74 \mathrm{~nm}$.

Keywords: 1989 nm; Ho:YAP; AO Q-switched laser

\section{Introduction}

$2 \mu \mathrm{m}$ holmium $\left(\mathrm{Ho}^{3+}\right)$ doped solid-state lasers have important application prospects in the fields of laser ranging, laser medical treatment, environmental monitoring, and optical communication due to its near-infrared window and safety to the human eye [1-8]. In addition, $2 \mu \mathrm{m} \mathrm{Ho}{ }^{3+}$ doped lasers were considered as good pump sources for mid-far infrared optical parametric oscillator (OPO) [9]. Compared with Ho:YAG, Ho:YLF and Ho:GdVO $\mathrm{G}_{4}$ crystals, Ho:YAP crystal has obvious advantages, such as wide absorption line, large absorption cross-section, anisotropy, short growth period, the output power was not easy to saturate, and so on. There are many absorption peaks in Ho:YAP crystal at $1.9 \mu \mathrm{m}$. For an a-cut Ho:YAP crystal, the absorption peaks included 1872 nm, $1907 \mathrm{~nm}, 1931 \mathrm{~nm}$, $1970 \mathrm{~nm}$ and $2045 \mathrm{~nm}$. For a b-cut Ho:YAP crystal, the absorption peaks included $1884 \mathrm{~nm}$, $1923 \mathrm{~nm}, 1946 \mathrm{~nm}, 1984 \mathrm{~nm}, 2023 \mathrm{~nm}$ and $2059 \mathrm{~nm}$ [10]. For a c-cut Ho:YAP crystal, the absorption peaks included 1915, 1941, 1980, and $1996 \mathrm{~nm}$ [11]. A maximum absorption peak for a-, b-, and c-cut Ho:YAP crystals was about $1976 \mathrm{~nm}$ [12].

In recent years, there are many reports on Ho:YAP lasers. In 2009, a Tm:YLF laser with the output wavelength of $1900 \mathrm{~nm}$ was used to pump the continuous wave Ho:YAP laser, was reported by Duan et al. [13]. The output power was $10.2 \mathrm{~W}$, with the slope efficiencies of $64.0 \%$, the optical-optical conversion efficiencies of $52.6 \%$, and the output wavelength of $2118 \mathrm{~nm}$. In 2011, a Tm:YLF laser with output wavelength of $1910 \mathrm{~nm}$ was used to pump the Ho:YAP (b-cut) Q-switched laser at room temperature, was reported by Yang et al. [14]. When the Q-switched repetition frequency was $5 \mathrm{kHz}$, the output power was $18.1 \mathrm{~W}$, the slope efficiencies was $45.9 \%$, the optical-optical conversion efficiencies was $36.5 \%$, and the output wavelength was $2118 \mathrm{~nm}$. In 2012, the theoretical and experimental analysis of a Ho:YAP (a-cut) crystal of $2 \mu \mathrm{m}$ laser was reported by Yang et al. [15]. The pump wavelength was $1900 \mathrm{~nm}$. The CW output power was $15.6 \mathrm{~W}$. The slope efficiencies was $63.7 \%$, the optical-optical conversion efficiencies was 54.5\%, and the output wavelength was $2118 \mathrm{~nm}$. In 2012, a Tm:YLF laser with an output wavelength of $1910 \mathrm{~nm}$ was used to pump the Q-switched Ho:YAP (a-cut) ring laser, was reported by Dai et al. [16]. When the Q-switched repetition frequency was $1 \mathrm{kHz}$, the output power of $10.17 \mathrm{~W}$ was obtained, the slope efficiencies was $60 \%$, the optical-optical conversion efficiencies was $29.5 \%$, and the output 
wavelength was $2119 \mathrm{~nm}$. In 2014, a Tm fiber laser with the output wavelength of $1910 \mathrm{~nm}$ was used to pump the Q-switched Ho:YAP (a-cut) laser, was reported by Wang et al. [17]. When the Q-switched repetition was $10 \mathrm{kHz}$, the output power of $11.0 \mathrm{~W}$ was obtained with the slope efficiencies of $62.1 \%$, the optical-optical conversion efficiencies of $26.3 \%$, and the output wavelength of $2118.0 \mathrm{~nm}$. In 2014, Tm:YLF laser with an output wavelength of $1910 \mathrm{~nm}$ was used to pump Ho:YAP (a-cut) Q-switched laser, was reported by Duan et al. [18]. When the Q-switched repetition frequency was $10 \mathrm{kHz}, 17.2 \mathrm{~W}$ output power was obtained, the slope efficiencies was $63.2 \%$, the optical-optical conversion efficiencies was $29 \%$, and the output wavelength was $2118 \mathrm{~nm}$. In 2016, a Tm fiber laser with the output wavelength of $1910 \mathrm{~nm}$ was used to pump a mode-locked Ho:YAP laser, was reported by Duan et al. [19]. The output power of $2.87 \mathrm{~W}$ was obtained, with a slope efficiency of $15 \%$, an optical-optical conversion efficiency of $11.9 \%$, and an output wavelength of $2118 \mathrm{~nm}$. In 2017, a Tm fiber laser with an output wavelength of $1941 \mathrm{~nm}$ was used to pump a Ho:YAP (c-cut) laser, as reported by Ting et al. [11]. The output power of $29 \mathrm{~W}$ was obtained with the slope efficiency of $42.8 \%$, the optical-optical conversion efficiency of $60.67 \%$, and the output wavelength of $2118 \mathrm{~nm}$. In 2018, a Tm fiber laser with an output wavelength of $1910 \mathrm{~nm}$ was used to pump a Ho:YAP (b-cut) laser, as reported by Duan et al. [20]. The output power was $10.5 \mathrm{~W}$, the slope efficiency was $53.2 \%$, the optical-optical conversion efficiency was $41 \%$, and the output wavelength was $2115 \mathrm{~nm}$. In 2020, a Tm:YAP laser with output wavelength of $1940 \mathrm{~nm}$ was used to pump the electro-optic Q-switched Ho:YAP (a-cut) laser reported by Lei et al. [21]. When the repetition frequency was $4 \mathrm{kHz}$, the output power was $6.5 \mathrm{~W}$, the slope efficiency was $50.6 \%$, the optical-to-optical conversion efficiency was $28 \%$, and the output wavelength was $2118 \mathrm{~nm}$.

As mentioned above, Tm-doped solid-state lasers or Tm fiber lasers with output wavelength of $1900 \mathrm{~nm}, 1910 \mathrm{~nm}$, or $1940 \mathrm{~nm}$ are often used as the pumping sources of Ho:YAP lasers. Although there was no pump source whose wavelength matches the strongest absorption peak of Ho:YAP crystal, the slope efficiency of Ho:YAP lasers was quite high under all kinds of situations, such as continuous or Q-switch or mode-locked operation, which means that the Ho:YAP crystal was one of the most promising $\mathrm{Ho}^{3+}$ doped lasers.

Under the premise of ensuring that the Ho:YAP crystal absorbs enough pumping power, the closer the wavelength of output laser and pumping laser, the smaller the quantum loss. However, there is not report on a Ho:YAP laser pumped by a $1989 \mathrm{~nm}$ laser, to our best knowledge.

In this paper, a Tm:YAP laser with the output wavelength of $1989 \mathrm{~nm}$ was selected for the first time as the pump source of Q-switched Ho:YAP laser. When the absorbed power was $30 \mathrm{~W}$, the output power of acousto-optic (AO) Q-switched Ho:YAP laser was $18.02 \mathrm{~W}$, and the pulse width was $104.2 \mathrm{~ns}$ at repetition frequency of $10 \mathrm{kHz}$. The corresponding slope efficiency was $70.11 \%$, and the optical-optical conversion efficiency was $43.03 \%$. The output center wavelength was $2129.22 \mathrm{~nm}$.

\section{Materials and Methods}

The experimental configuration was shown in Figure 1.

To achieve high output power of Q-switched Ho:YAP laser, four semiconductor lasers (Type: SHCC-FCP-60-200-795-S, Shanghai Chuchuang Optical Machinery Technology Co., Ltd., Shanghai, China) with a central wavelength of $795 \mathrm{~nm}$ were used as pumping sources of Tm:YAP laser.

Two Tm:YAP crystals with the same parameter were used in the experiment. The Tm:YAP crystal had a cross-section size of $4 \mathrm{~mm} \times 4 \mathrm{~mm}$, a length of $12 \mathrm{~mm}$, and $\mathrm{Tm}^{3+}$ doping concentration of 3 at.\%. Both ends of the crystal were coated with high transmissivity at $1989 \mathrm{~nm}$ and $795 \mathrm{~nm}$. The crystal was wrapped in thick indium foil with the thickness of $0.1 \mathrm{~mm}$ and placed in a copper heat sink. The heat sink was cooled by water, which was kept at $18{ }^{\circ} \mathrm{C}$. 


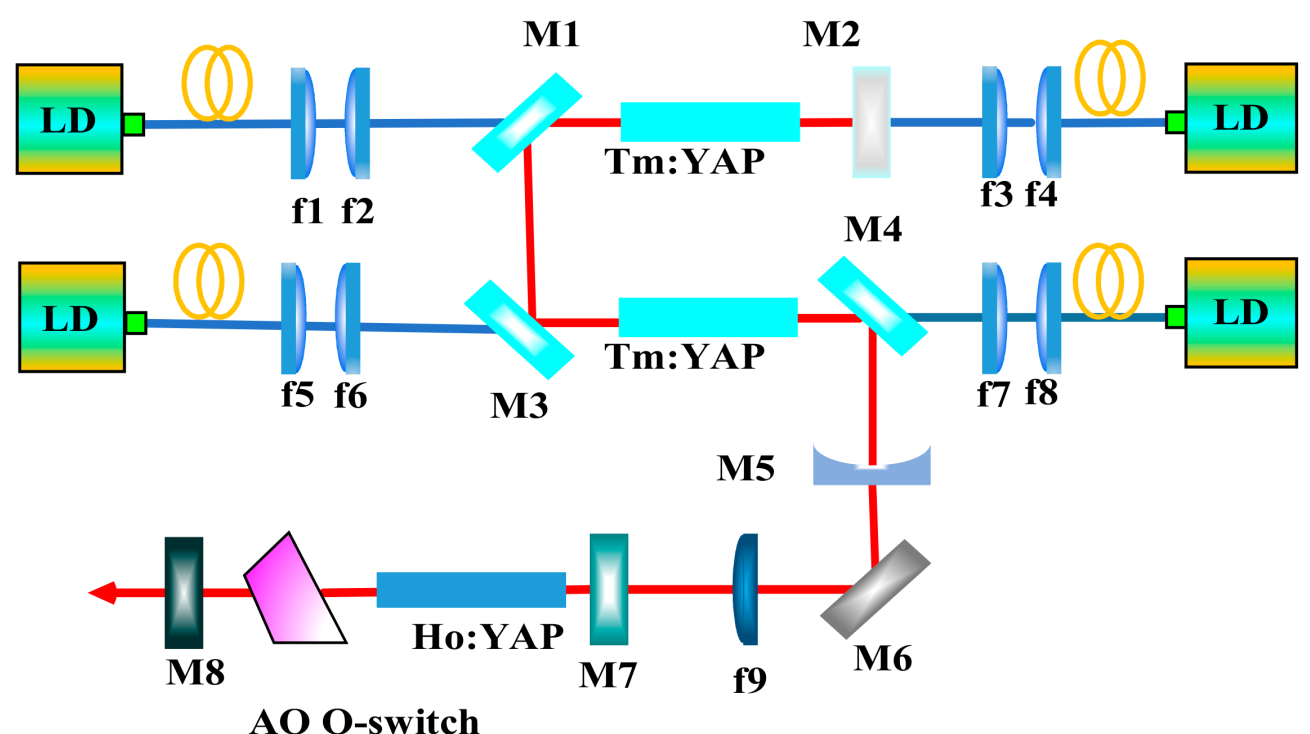

Figure 1. Acousto-optic Q-switched Ho:YAP laser pumped by $1989 \mathrm{~nm}$ laser.

The output power of Tm:YAP laser was improved by using a laser diode (LD) doubleended pump structure. The cavity was formed by flat mirrors M1, M2, M3, M4, and a concave mirror M5. M1, M3 and M4 were $45^{\circ}$ mirrors coated with high transmissivity at $795 \mathrm{~nm}$ and high reflectivity at $1989 \mathrm{~nm}$. M2 was a $0^{\circ}$ mirror coated with high transmissivity at $795 \mathrm{~nm}$ and high reflection at $1989 \mathrm{~nm}$. Curvature radius of the output coupler M5 was $300 \mathrm{~mm}$ and coated with transmissivity of $10 \%$ at $1989 \mathrm{~nm}$.

Good mode matching between the pumping beam and oscillating beam of the Tm:YAP laser was achieved by adjusting the focus coupling mirrors, $\mathrm{f} 1=\mathrm{f} 4=\mathrm{f} 5=\mathrm{f} 8=25 \mathrm{~mm}$, $\mathrm{f} 2=\mathrm{f} 3=\mathrm{f} 6=\mathrm{f} 7=50 \mathrm{~mm}$. The focus lenses were anti-reflection coated at $795 \mathrm{~nm}$. We measured the pump power before the lenses and after M1, M2, M3 and M4, and we calculated the pump transmission to be about $90 \%$.

The resonator of Ho:YAP was a straight cavity composed of M7 and M8. M7 was coated with high transmissivity at $1989 \mathrm{~nm}$ and high reflectivity at $2118 \mathrm{~nm}$. Curvature radius of the output coupler M8 was $100 \mathrm{~mm}$ and coated with high transmissivity at $1989 \mathrm{~nm}$ and transmissivity of $20 \%$ at $2118 \mathrm{~nm}$. The cavity length of Ho:YAP was $70 \mathrm{~mm}$.

The size of Ho:YAP crystal was $4 \mathrm{~mm} \times 4 \mathrm{~mm} \times 25 \mathrm{~mm}$, and the $\mathrm{Ho}^{3+}$ doped concentration was 0.8 at. \%. Both ends of the crystal were coated with high transmissivity at $1989 \mathrm{~nm}$ and $2118 \mathrm{~nm}$. The crystal was wrapped in thick indium foil with the thickness of $0.1 \mathrm{~mm}$ and placed in a copper heat sink. The heat sink was cooled by water, which was kept at $18{ }^{\circ} \mathrm{C}$.

A quartz acousto-optic Q-switch (QS041-10M-HI8 and the drive model MQH041100DM-A05, Gooch\&Housego Co., Ltd, Ilminster, Somerset, UK) with a length of $46 \mathrm{~mm}$ and aperture of $2.0 \mathrm{~mm}$ was employed for Q-switching operation. Both ends of the Qswitch crystal were coated with high transmissivity at $2118 \mathrm{~nm}$. The radio frequency was $40.68 \mathrm{MHz}$, and the maximum radio frequency power was $50 \mathrm{~W}$. The threshold of damage was larger than $500 \mathrm{MW} / \mathrm{cm}^{2}$. The AO Q-switch crystal was cooled by a water cooler at $18^{\circ} \mathrm{C}$.

In order to facilitate the adjustment and realize the good mode matching between the pump light and the oscillating light, plat mirror M6 and focus lenses f9 and f10 were used. M6 was a $45^{\circ}$ full mirror coated with high-reflection at $1989 \mathrm{~nm}$. The focus lens $\mathrm{f} 9=50 \mathrm{~mm}$ was anti-reflection (AR) coated at $1989 \mathrm{~nm}$. 


\section{Results and Discussion}

The absorptance of Tm:YAP crystal to pump light was $92 \%$. The output power of Tm:YAP laser was measured with the power meter F150A (OPHIR, Jerusalem, Israel), as shown in Figure 2. The output power of the laser varied linearly with the absorbed power. The threshold power of the laser was $11 \mathrm{~W}$. The maximum output power of the Tm:YAP laser was $50 \mathrm{~W}$, and the slope efficiency was $41.32 \%$. The central wavelength at the maximum output power was $1989.01 \mathrm{~nm}$, which was measured using the spectrometer (AQ6370 of Yokogawa, Musashino, Tokyo, Japan), as shown in Figure 3.

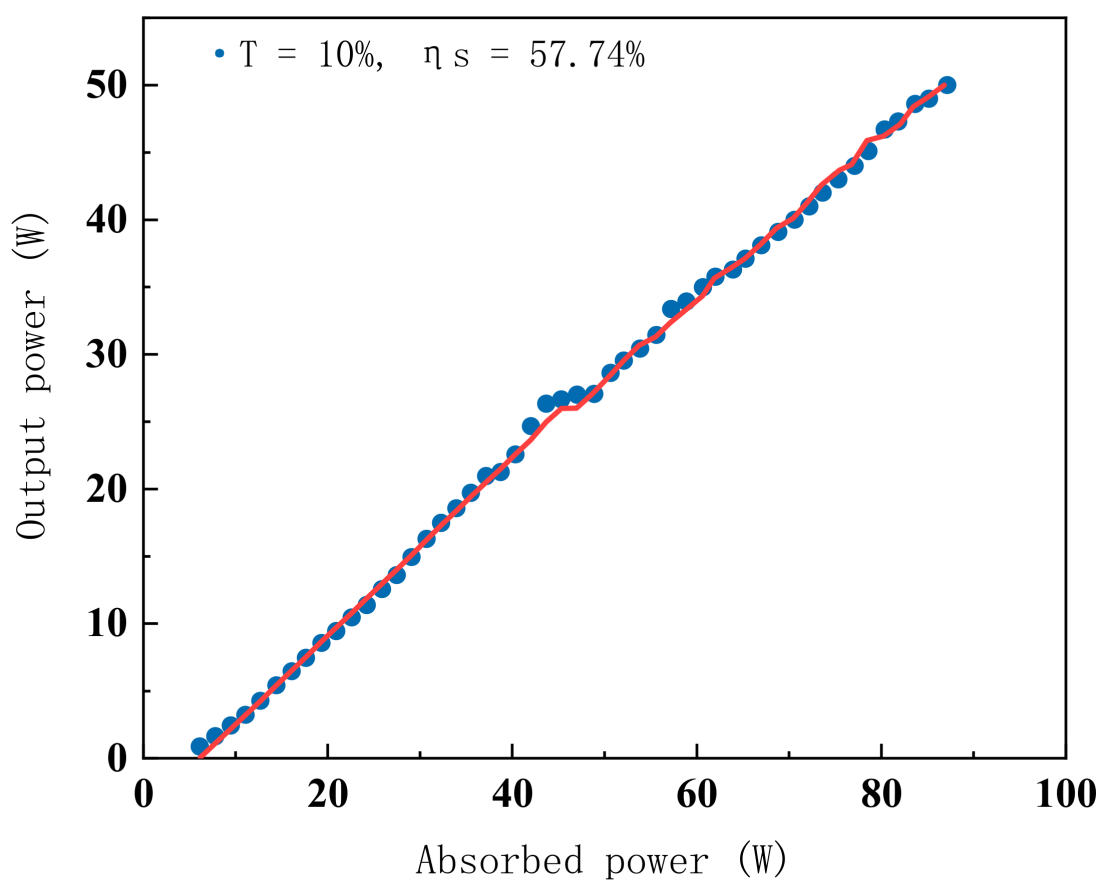

Figure 2. Output power versus absorbed power of Tm:YAP laser.

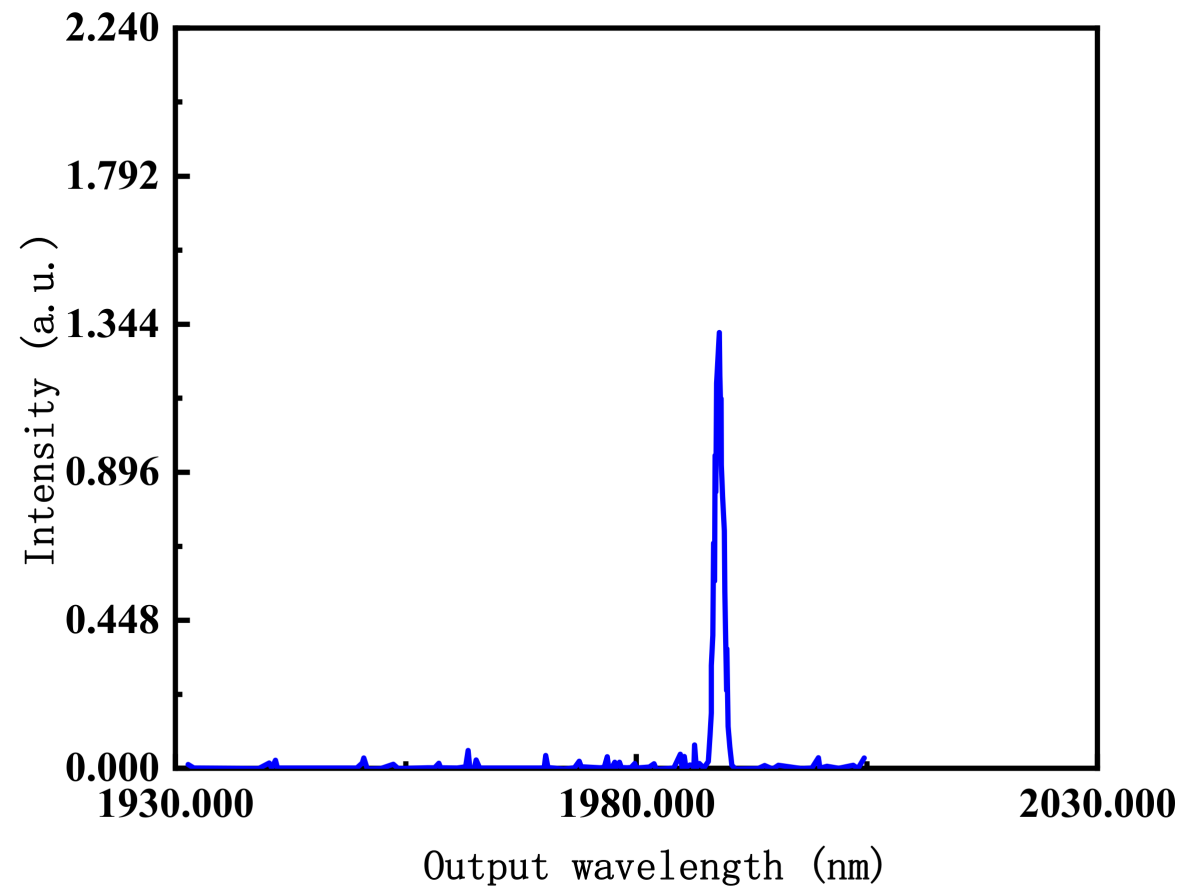

Figure 3. Output spectrum of Tm:YAP laser. 
The central wavelengths of Tm:YAP laser versus output power were shown in Figure 4. When the output power of continuous Tm:YAP laser varied from $0.5 \mathrm{~W}$ to $50 \mathrm{~W}$, the center wavelength of the Tm:YAP laser remained between $1986.00 \mathrm{~nm}$ and $1990.00 \mathrm{~nm}$. The fluctuation of the center wavelength was affected by the accuracy of temperature control of the Tm:YAP crystal. However, the output wavelength of the Tm:YAP laser was always in the absorption line width of the Ho:YAP crystal, which means that it can be used as the pump source of the Ho:YAP laser.

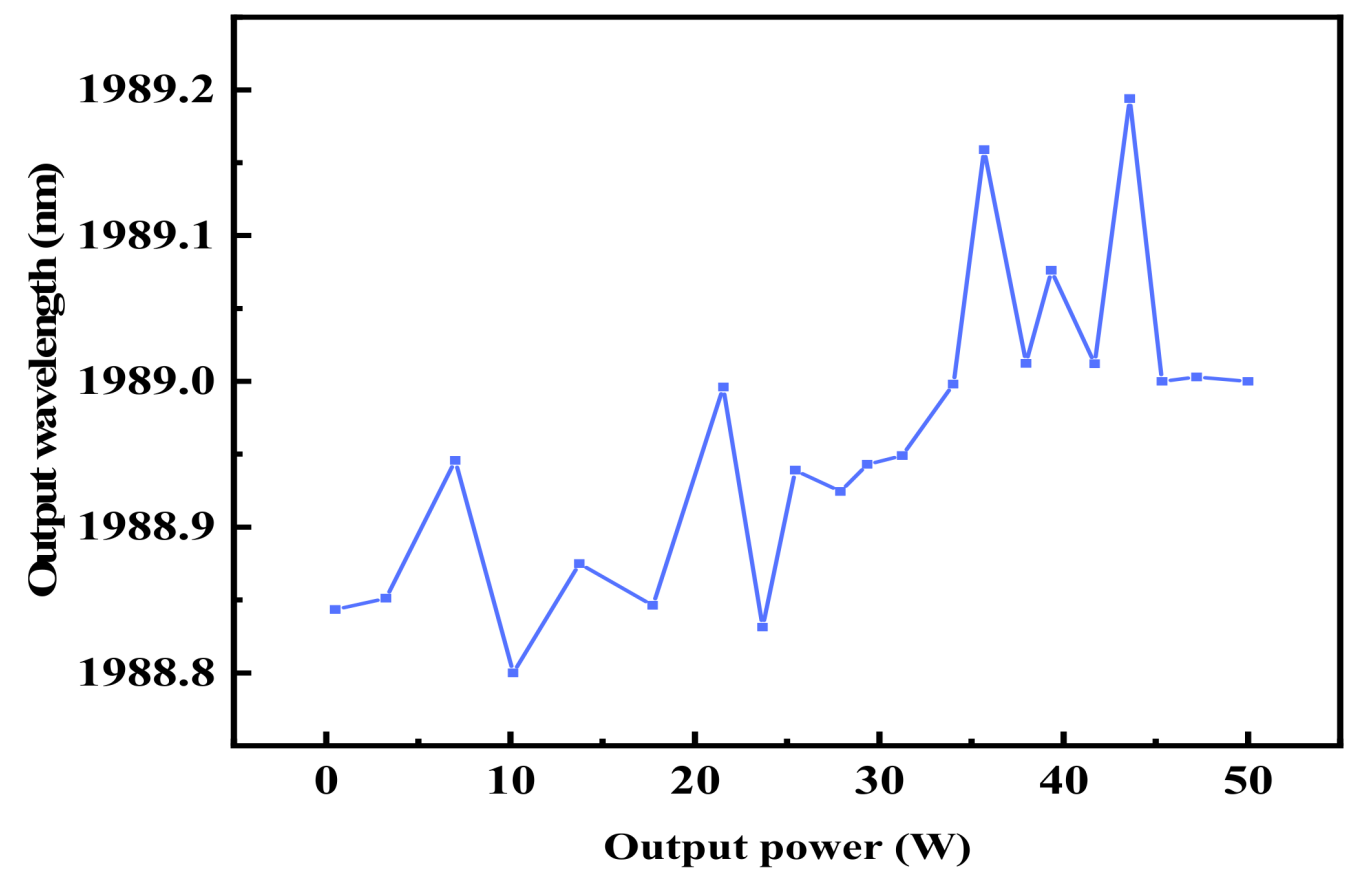

Figure 4. Output wavelength of Tm:YAP laser versus output power.

With Tm:YAP laser as the pump source with the maximum output power of $50 \mathrm{~W}$, the experimental study of acousto-optic Q-switched Ho:YAP laser was carried out. The average power of the laser output was measured by a power meter (30A-BB-18, OPHIR, Jerusalem, Israel), and the pulse width of the laser output was measured by an oscilloscope (DPO3054, Tektronix, Beaverton, Oregon, U.S.) and a pulse width detector (PCI-3TE-12, VIGO System S.A., Warsaw, Poland).

As shown in Figure 5, the average output powers of an AO Q-switched Ho:YAP laser versus pump power were achieved under repetition frequency of $1 \mathrm{kHz}, 5 \mathrm{kHz}$ and 10 $\mathrm{kHz}$. At pump power of $50 \mathrm{~W}$, the maximum average output powers of AO Q-switched Ho:YAP laser were 14.2, 15.84, and $18.02 \mathrm{~W}$, with the slope efficiencies of 55.25, 61.66, and $70.11 \%$, respectively. The output pulse width of the Q-switched Ho:YAP laser versus the pump power was achieved under different repetition frequencies, as shown in Figure 6. At absorbed power of $30 \mathrm{~W}$, the narrowest output pulse widths were $101.7 \mathrm{~ns}, 103.1 \mathrm{~ns}$ and $104.2 \mathrm{~ns}$ under repetition frequency of $1 \mathrm{kHz}, 5 \mathrm{kHz}$, and $10 \mathrm{kHz}$, respectively. 


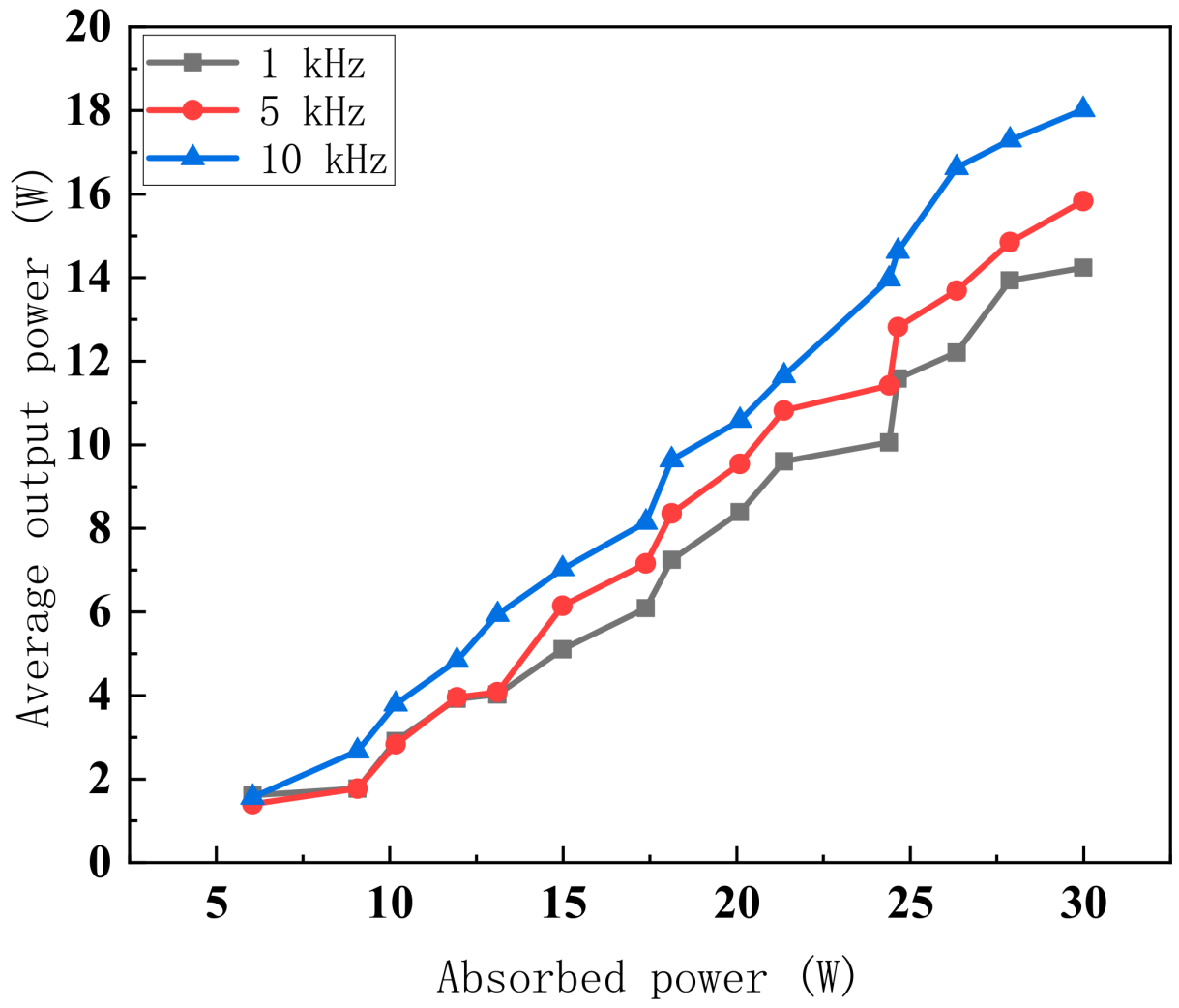

Figure 5. Average output power of Q-switched Ho:YAP laser versus absorbed power.

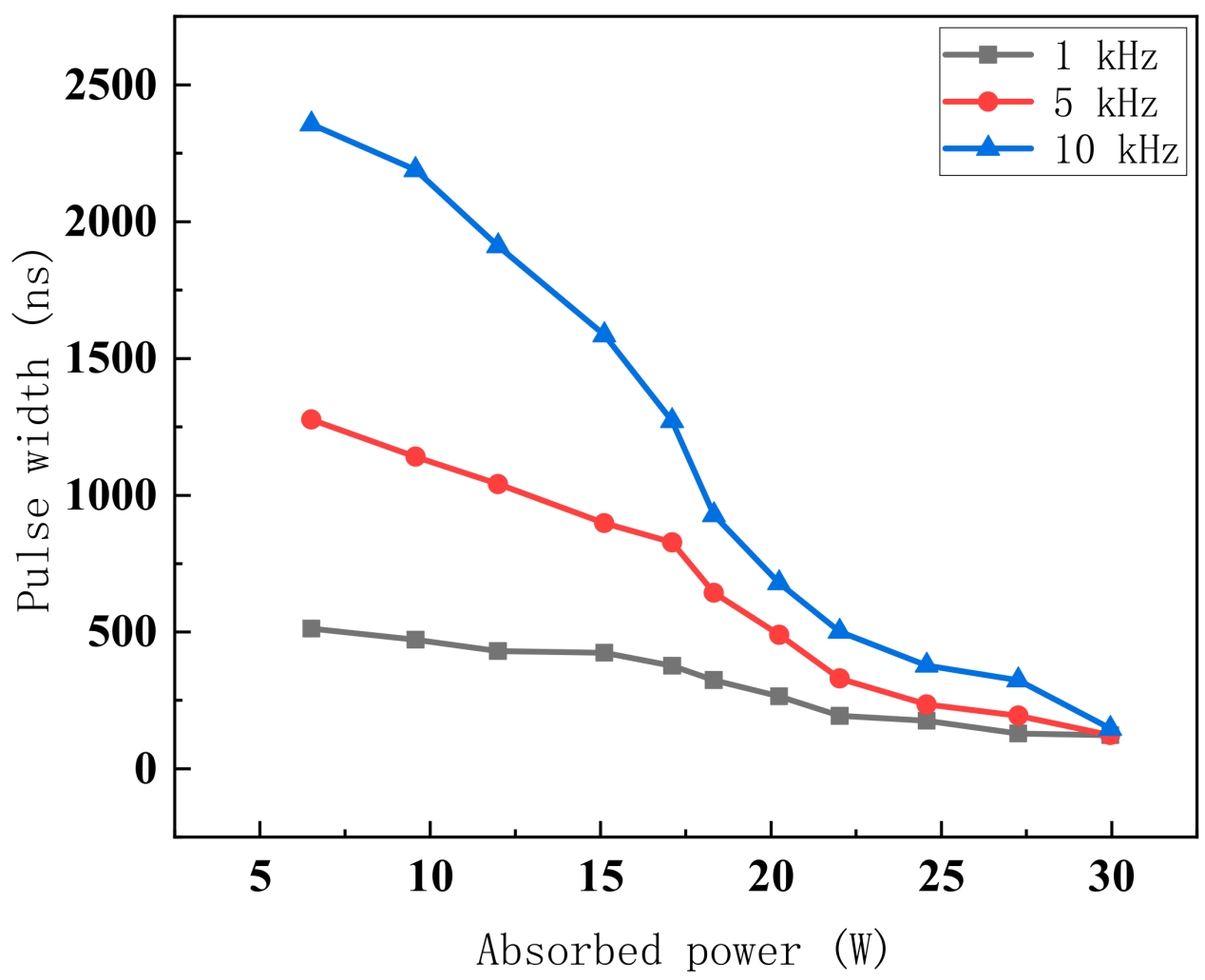

Figure 6. Output pulse width of Q-switched Ho:YAP laser versus absorbed power.

The central wavelength of the AO Q-switched Ho:YAP laser was measured using the spectrometer (AQ6370, Yokogawa, Musashino, Tokyo, Japan). The central wavelengths at 
the maximum output average power were $2129.29 \mathrm{~nm}, 2129.47 \mathrm{~nm}$ and $2129.22 \mathrm{~nm}$, with output linewidths of $0.77 \mathrm{~nm}, 0.75 \mathrm{~nm}$ and $0.74 \mathrm{~nm}$ under repetition frequency of $1 \mathrm{kHz}$, $5 \mathrm{kHz}$ and $10 \mathrm{kHz}$, respectively.

Figure 7 showed the output spectrum of a Q-switched Ho:YAP laser at an output average power of $18.02 \mathrm{~W}$ and repetition frequency of $10 \mathrm{kHz}$. While, Figure 8 gave the output width of Q-switched Ho:YAP laser under the same condition.

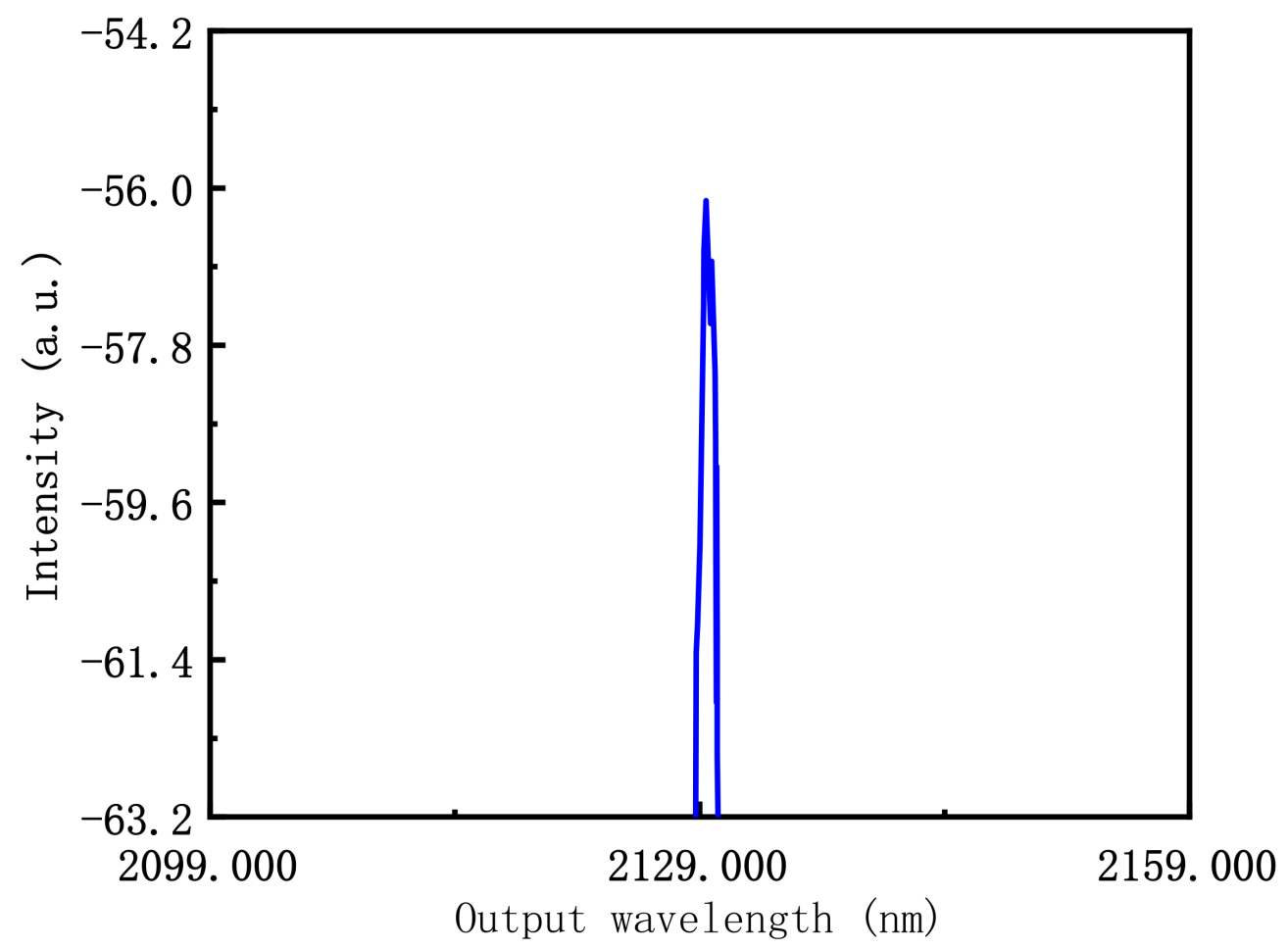

Figure 7. Output spectrum of AO Q-switched Ho:YAP laser.

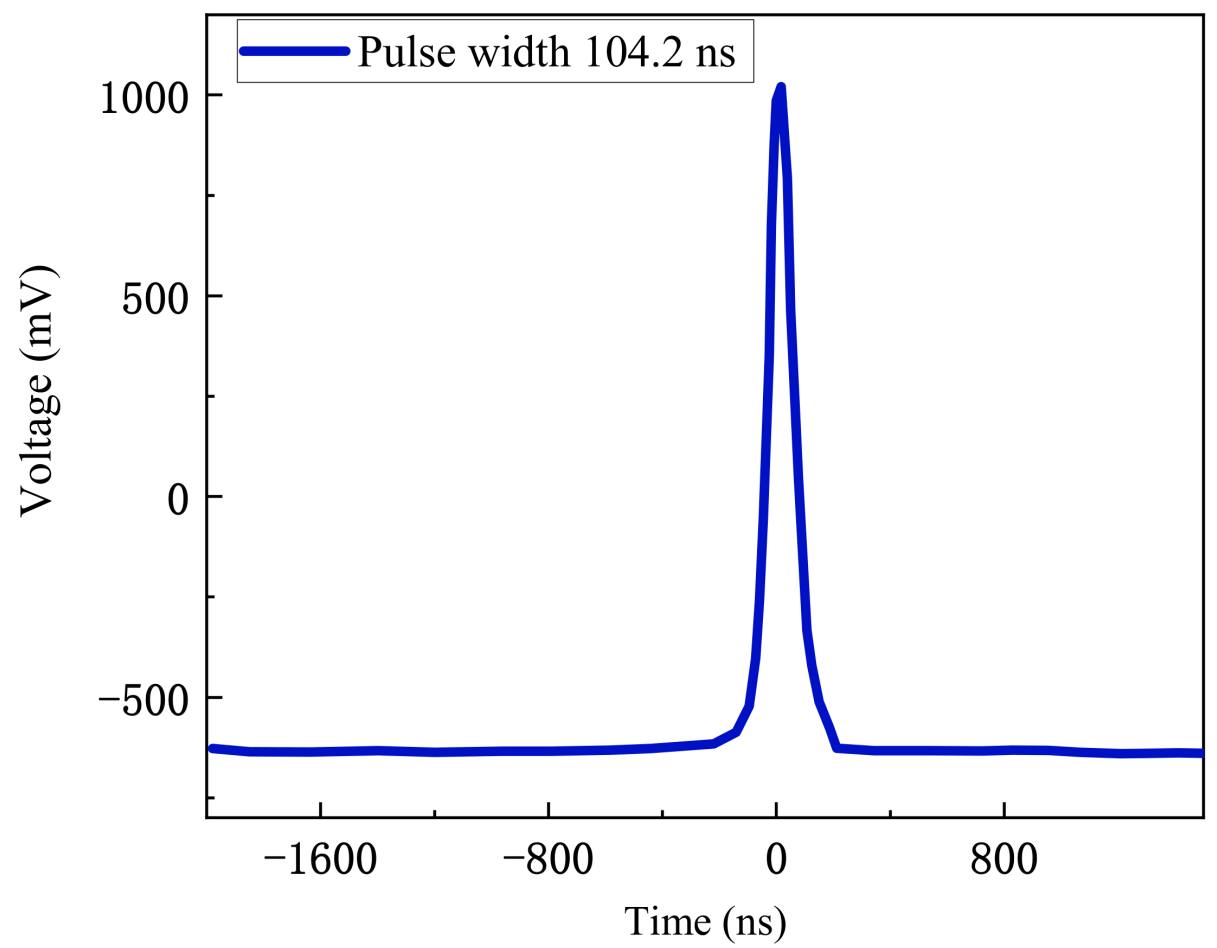

Figure 8. Output pulse width of AO Q-Switched Ho:YAP laser. 


\section{Conclusions}

We demonstrated an AO Q-switched Ho:YAP laser pumped by the $1989 \mathrm{~nm}$ laser for the first time. Under the pump power of $50 \mathrm{~W}$, at a PRF of $1 \mathrm{kHz}$, the average output power of $14.2 \mathrm{~W}$ Ho:YAP laser was obtained, with the slope efficiency of $55.25 \%$, the pulse width of $101.7 \mathrm{~ns}$, and the central wavelength of $2129.29 \mathrm{~nm}$. At a PRF of $5 \mathrm{kHz}$, the average output power of $15.84 \mathrm{~W}$ laser was obtained, with the slope efficiency of $61.66 \%$, the pulse width of $103.1 \mathrm{~ns}$, and the central wavelength of $2129.47 \mathrm{~nm}$. At a PRF of $10 \mathrm{kHz}$, the average output power of $18.02 \mathrm{~W}$ laser was obtained, with the slope efficiency of $70.11 \%$, the pulse width of $104.2 \mathrm{~ns}$, and the central wavelength of $2129.22 \mathrm{~nm}$.

Author Contributions: Conceptualization, C.N., Y.W. and C.W.; methodology, T.D. and C.N.; software, C.N., Y.W. and L.Z.; validation, C.N. and Y.W.; formal analysis, X.C. and L.Z.; investigation, Y.J., C.N., L.Z. and X.C.; resources, C.W. and T.D.; data curation, Y.W., Y.J. and C.N.; writing—original draft preparation, C.N.; writing-review and editing, C.W. and Y.W.; visualization, C.N.; supervision, T.D.; project administration, C.W.; funding acquisition, C.W. All authors have read and agreed to the published version of the manuscript.

Funding: This research was funded by Study on the radiation mechanism and output characteristics of single longitudinal mode laser with tunable injection frequency locked $2 \mu \mathrm{m}$ pulses, grant number 202002041JC and the APC was funded by Science and Technology Department of Jilin Province in China.

Data Availability Statement: The data presented in this study are available on request from the corresponding author.

Acknowledgments: This work is supported by Science and Technology Department of Jilin Province in China (Grant No. 202002041JC).

Conflicts of Interest: The authors declare no conflict of interest.

\section{References}

1. Wu, C.T.; Jiang, Y.; Dai, T.Y.; Zhang, W.Q. Research Progress of $2 \mu \mathrm{m}$ Ho-doped Solid-state Laser. Chin. J. Lumin. 2018, 39, 1584-1597.

2. Scholle, K.; Lamrini, S.; Koopmann, P. $2 \mu \mathrm{m}$ Laser Sources and Their Possible Applications In Frontiers in Guided Wave Optics and Optoelectronics; IntechOpen: London, UK, 2010; Volume 21, pp. 471-500.

3. Li, Z.; Heidt, A.M.; Daniel, J.M.O.; Jung, Y.; Alam, S.U.; Richardson, D.J. Thulium-Doped Fiber Amplifier for Optical Communications at 2 Microns. Opt. Express 2013, 21, 9289-9297. [CrossRef] [PubMed]

4. Lombard, L.; Valla, M.; Augère, B.; Planchat, C.; Goular, D.; Bourdon, P.; Canat, G. Eyesafe Coherent Detection Wind Lidar Based on a Beam-Combined Pulsed Laser Source. Opt. Lett. 2015, 40, 1030-1033. [CrossRef] [PubMed]

5. Gibert, F.; Edouart, D.; Cénac, C.; Le Mounier, F. 2- $\mu$ m High-Power Multiple-Frequency Single-Mode Q-Switched Ho:YLF Laser for DIAL Application. Appl. Phys. B 2014, 116, 967-976. [CrossRef]

6. Peplow, P.V.; Chung, T.Y.; Baxter, G.D. Laser Photostimulation $(660 \mathrm{~nm})$ of Wound Healing in Diabetic Mice Is Not Brought About by Ameliorating Diabetes. Lasers Surg. Med. 2012, 44, 26-29. [CrossRef] [PubMed]

7. Wu, Y.; Zhai, G.; Yao, Z.H. Development of $2 \mu \mathrm{m}$ Band Lasers. Laser J. 2008, 29, 3-4.

8. Ding, Y. Characteristics of $2 \mu \mathrm{m}$ Single Doped Ho Vanadate Solid State Laser. Ph.D. Thesis, Harbin Institute of Technology, Harbin, China, 2015.

9. Xin, Y.; Ye, B.; Fang, W.L. Application and progress of holmium laser. Laser Optoelectron. Prog. 2012, 49, $22-27$.

10. Yang, X.T. Room Temperature Resonant Pumping Ho: Experimental Study of YAP Laser. Ph.D. Thesis, Harbin Institute of Technology, Harbin, China, 2009.

11. Yu, T.; Peng, Y.J.; Ye, X.S.; Chen, W.B. Study on Ho: YAP laser technology pumped by thulium optical laser. In Seminar on Optical Technology 2017 and Collection of Interdisciplinary Forum; Shanghai Infrared and Remote Sensing Society: Shanghai, China; Yunnan Optical Society: Yunnan, China, 2017; Volume 6.

12. Wu, X.S. Research on Ho: YAP Single-Frequency Laser. Ph.D. Thesis, Harbin Institute of Technology, Harbin, China, 2019.

13. Duan, X.M.; Yao, B.Q.; Li, G.; Wang, T.H.; Yang, X.T.; Wang, Y.Z.; Zhao, G.J.; Dong, Q. High Efficient Continuous Wave Operation of a Ho: YAP Laser at Room Temperature. Laser Phys. Lett. 2009, 6, 279-281. [CrossRef]

14. Yang, X.T.; Ma, X.Z.; Li, W.H.; Liu, Y. Q-Switched Ho: YAlO 3 Laser Pumped by Tm:YLF Laser at Room Temperature. Laser Phys. 2011, 21, 2064-2067. [CrossRef]

15. Yang, X.T.; Liu, Y.; Li, W.H.; Ju, Y.L. Theoretical and Experimental Analysis of $2 \mu \mathrm{m}$ Laser Crystal Ho:YAP. Infrared Laser Eng. 2012, 41, 1733-1737. 
16. Dai, T.Y.; Ju, Y.L.; Shen, Y.J.; Wang, W.; Yao, B.Q.; Wang, Y.Z. High-Efficiency Continuous-Wave and Q-Switched Operation of a Resonantly Pumped Ho:YAP Ring Laser. Laser Phys. 2012, 22, 1292-1294. [CrossRef]

17. Wang, Z.; Ma, X.; Li, W. Efficient Ho: YAP Laser Dual-End-Pumped by Tm Fiber Laser. Opt. Rev. 2014, 21, 150-152. [CrossRef]

18. Duan, X.M.; Yang, C.H.; Shen, Y.J.; Yao, B.Q.; Ju, Y.L.; Wang, Y.Z. High-Power in-Band Pumped a -Cut Ho: Yap Laser. J. Russ. Laser Res. 2014, 35, 239-243. [CrossRef]

19. Duan, X.M.; Lin, W.M.; Cui, Z.; Yao, B.Q.; Li, H.; Dai, T.Y. Resonantly Pumped Continuous-Wave Mode-Locked Ho:YAP Laser. Appl. Phys. B 2016, 122, 88. [CrossRef]

20. Duan, X.; Li, L.; Shen, Y.; Yao, B. Efficient Ho:YAP Laser Dual End-Pumped by a Laser Diode at $1.91 \mu \mathrm{m}$ in a Wing-Pumping Scheme. Appl. Phys. B 2018, 124, 1-6. [CrossRef]

21. Guo, L.; Zhao, S.; Li, T.; Qiao, W.; Ma, B.; Yang, Y.; Yang, K.; Nie, H.; Zhang, B.; Wang, R.; et al. In-band Pumped, High-Efficiency LGS Electro-Optically Q-Switched 2118 nm Ho:YAP Laser with Low Driving Voltage. Opt. Laser Technol. 2020, 126, 106015. [CrossRef] 